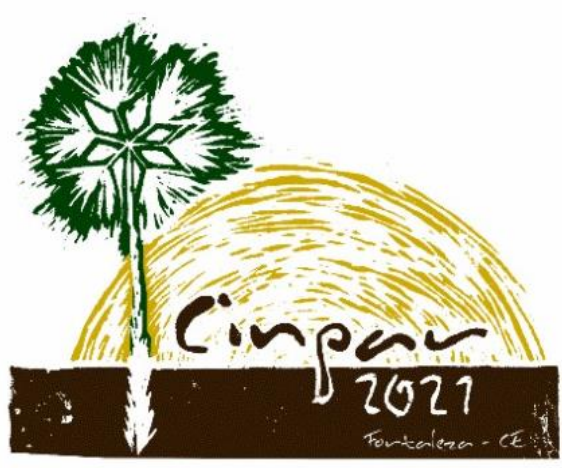

XVII Congresso Internacional sobre Patologia e

Reabilitação das Construções

XVII Congreso Internacional sobre Patología y Rehabilitación de las Construcciones

XVII International Conference on Pathology and Constructions Rehabilitation

FORTALEZA (Brasil), 3 a 5 de junho de 2021

https://doi.org/10.4322/CINPAR.2021.012

\title{
Current panorama of concrete evaluation using Non-Destructive Methods
}

\author{
Kevin Tenório Lobo Martins SOUZA, Kaio Cézar da Silva OLIVEIRA² \\ ${ }^{1}$ Universidade Federal de Alagoas, Maceió - AL, Brazil, kevin.tenorio98@gmail.com \\ 2 Universidade Federal de Santa Catarina, Florianópolis - SC, Brazil, ufsc.kcso@gmail.com
}

\begin{abstract}
:
This article proposes a review of the non-destructive tests (NDT) of concrete evaluation. NDT's are widely explored and studied, as they have great potential in the inspection process for concrete elements. Several factors favour the use of non-destructive techniques in this analysis, being the subject of several studies today. Due to the advancement of technology within civil construction, there was a great acceptance of these techniques in the process of assessing strength, uniformity, durability, and other properties of concrete. The non-use of NDT's is, in most cases, due to the lack of full knowledge of the techniques that could be applied. In this way, the article proposes to approach this theme, describing and exposing some examples where the application of the NDT's was successful in concrete structures.
\end{abstract}

Keywords: NDT, Concrete, Civil, Evaluation.

\section{Introduction}

In times when technology has been developing at a fast pace, we can see how much it has benefited civilizations over time. The constant need to improve products and production processes, from the design of the project to the delivery of the product, provides even more technological development, with all stages interconnected and dependent on each other. Thus, to be successful in the final product, it is necessary to efficiently apply means that enable an early detection of possible failures and pathologies, whether they are detected in the raw material or the production process and the final product.

The most used material in the world, after water, concrete is famous due to its excellent durability and ease in the production process, from its making to its final application. Despite all the advantages, many of the concrete structures are exposed to actions that can cause their degradation. This degradation process will affect the structural performance of the part and may even cause serious accidents. In addition to the environmental actions, the concrete can suffer degradation when poorly dosed or the project is poorly designed or executed. All the problems mentioned will be responsible for the appearance of different types and levels of pathological damage, so the search for processes that can predict, or assist in the recovery of these structures is extremely important.

It is common knowledge that non-destructive testing (NDT) has been widely explored in civil engineering in recent decades. When talking about NDT, immediately refer to a set of tests that allow the researcher to obtain data about the material, system, or any specific component, without any permanent alteration or damage to it. NDT can be subdivided into two classes: non-destructive examination or evaluation (NDE) and non-destructive inspection (NDI), which indicates the diverse range of applications for this type of test. Despite its advantages, care is still needed in its application since structures with different types of materials can be overly complex to evaluate with these methods. The application of these NDT's enables both the inspection and evaluation of civil works, as well as the study of materials applied in construction. Usually, the 
costs of applying these tests are lower and require a smaller technical staff, but each case must be evaluated individually looking for the best NDT for that situation. Of a non-invasive nature, NDT's are remarkably interesting tools in the quality control of materials and products, having been present in the automotive, electrical, aerospace, and naval industries for a longer time.

Through NDT's it is possible to evaluate the resistance of a given body since it is related to the density of the material. Tests such as thermography, ultrasound, and magnetic resonance can perform this type of analysis of concrete since they can sweep the entire interior of the piece. On the other hand, techniques such as Digital Image Correlation (DIC) bring the possibility of analyzing the behavior of bodies through the analysis of their surface, making it possible to evaluate them from the displacement of the body, such as monitoring the opening of cracks and the identification of constitutive parameters of the material, such as the modulus of elasticity. Thus, this article highlights the operation of non-destructive techniques and their applications in the evaluation of concrete structures.

\section{Non-Destructive Methods}

Once the central idea of this work was presented, the NDTs that were mostly applied in the field of civil engineering were selected, more specifically in the evaluation of concrete and the structures that contain this material.

\subsection{X-Ray Micro Computed Tomography (Micro-CT)}

Micro-CT is an imaging technique that consists in creating three-dimensional image representations of the specimen's interior out of multiple two-dimensional X-ray projections. Since the development and first applications of Röntgen's X-ray in 1895, scientists began to dabble in the possibility of generating threedimensional images using the technique. The idea was mathematically proven by Johan Radon in 1917, who developed the named Radon transform for the reconstruction of an $n$-dimensional specimen from $(n-1)$ dimensional projections. However, it was only between 1964 and 1975 that Hounsfield and Cormack developed the theory, concept and machine of the first device for computed tomography (Figure 1) (Beckmann, 2006).

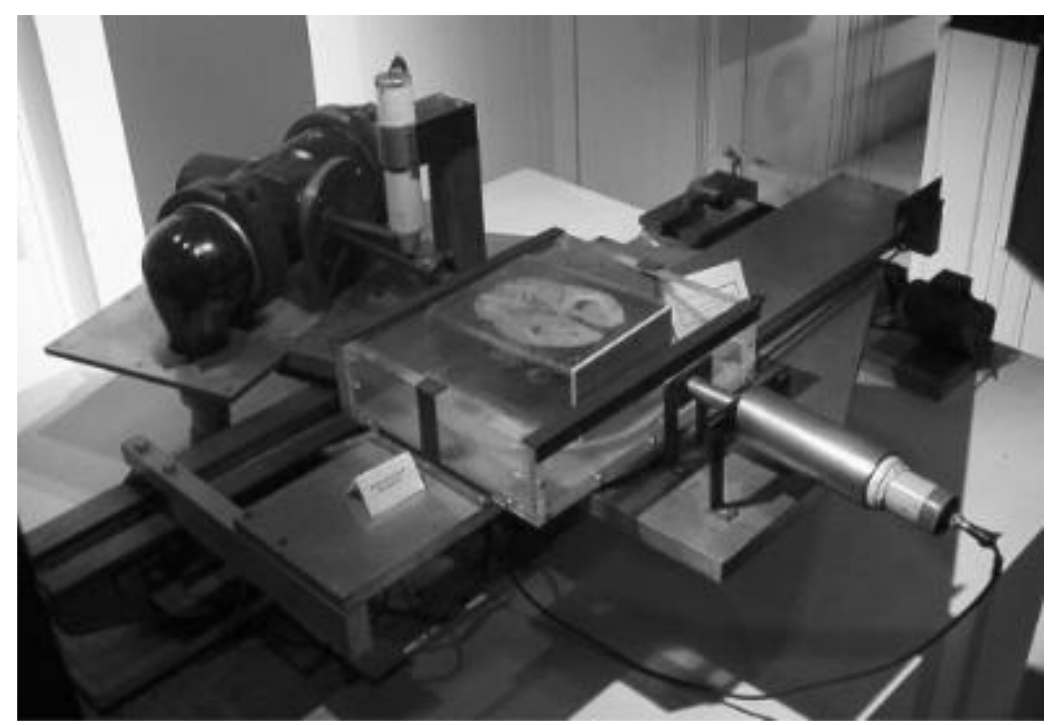

Figure 1 - The first Micro-CT device (Beckmann, 2006)

As denoted in Perlin (2011), the technique works by emitting ionizing radiation to the specimen in a certain wavelength called X-ray. The beam's energy is absorbed by the interaction with the materials it passes through. Therefore, an X-ray projection is an image representation of the energy of the beam that reaches the receptor. By emitting beams through a whole plane of the specimen, a $2 \mathrm{D}$ image is formed. The conjunction of a series of 2D images is used to form the 3D representation of the object, as seen in Figure 2. 


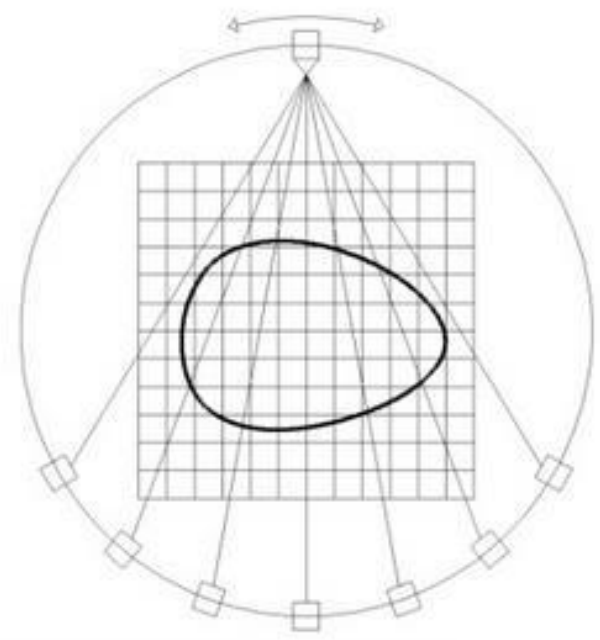

Figure 2 - Receptor movement during Micro-CT (Perlin, 2011)

In the recent days, the method has been widely used in several applications other than in medicine, such as food studies, insect and fish biology, geology and in the studies of cementitious materials. In the scope of concrete analysis, Micro-CT is already a common technique. It is applied to the study of the internal structure of concrete specimens, investigating phase identification, porosity, corrosion, density, damage and fiber reinforcement (du Plessis and Boshoff, 2019).

In Thomas et al. (2020), the porosity and material properties of multi-recycled aggregate concrete was studied using Micro-CT scans of the specimens. The study evaluates the change in material properties as they are recycled into new specimens, starting from a source concrete mix using limestone coarse aggregate. After characterization, the source specimen is crushed to obtain the recycled aggregate that is used in the 1st generation of recycled concrete specimen. The same process happens to form the 2 nd and 3 rd generations. The results demonstrates that due to the loss of properties, it is only possible to recycle concrete a finite number of times. Figure 3 shows the 3D image of the source specimen compared to the 3rd generation specimen.
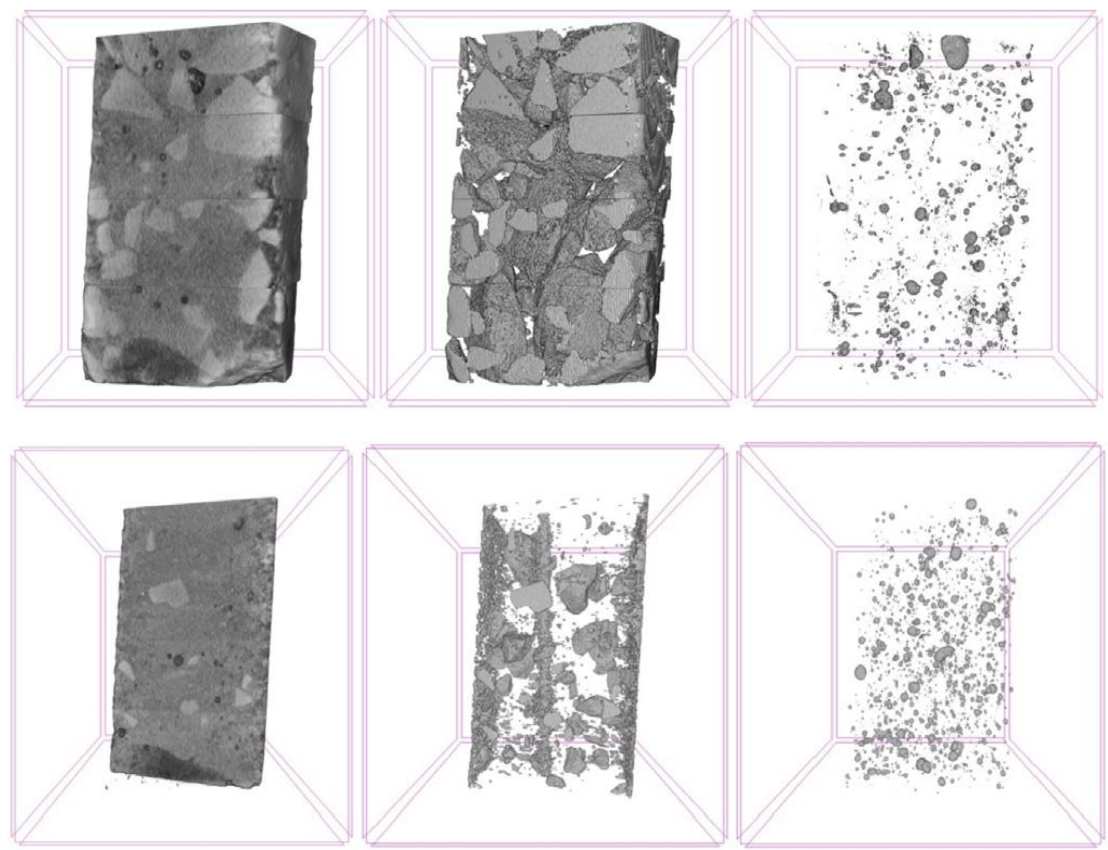

Figure 3 - Specimen (left), course limestone aggregate (center) and closed porosity (right). On the first row is the source specimen and on the second is the 3rd recycling generation (Thomas et al. (2020)) 
Pham et al. (2020) uses Micro-CT to compare the porosity and fiber alignment between cast and 3D printed concrete specimens. The results show that the high-quality printed concrete has a lower pore content than cast concrete. Also, it shows that more than $90 \%$ of the fibers align within $0^{\circ}-30^{\circ}$ from the filament orientation (Figure 4).
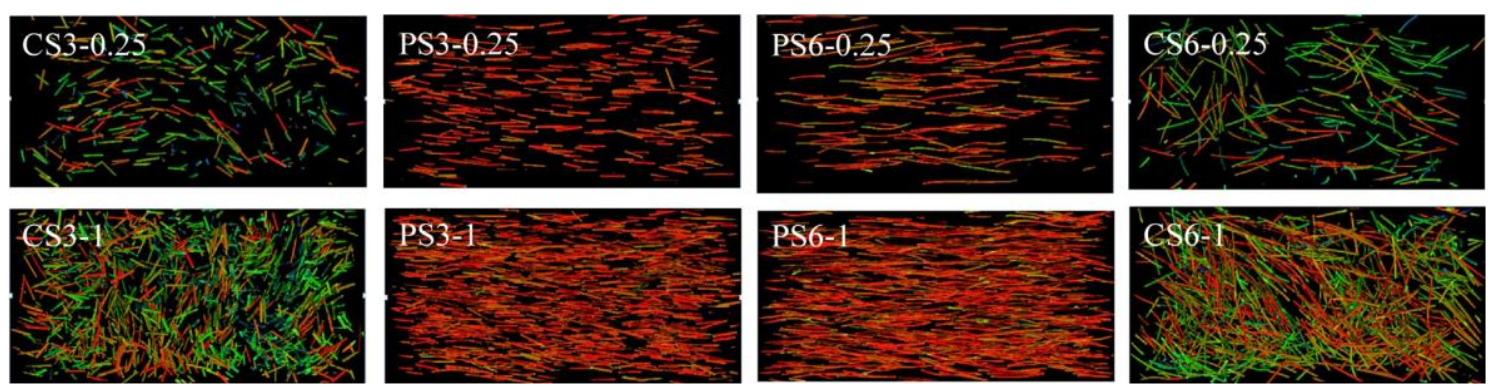

Figure 4 - Fiber orientation in printed and cast specimens reinforced with $0.25 \%$ and $1 \%$ by volume steel fibres of

$3 \mathrm{~mm}$ and $6 \mathrm{~mm}$ lengths (Pham et al. (2020))

\subsection{Thermography}

Thermography can be defined as a technique that allows the radiation emitted by heat to be transformed into an image. Using charged coupled devices to create electrical signals from infrared light emitted by the heat in the specimen, infrared cameras (Figure 5) can generate high resolution images that can be used in the scope of medicine, geology, military and material engineering.

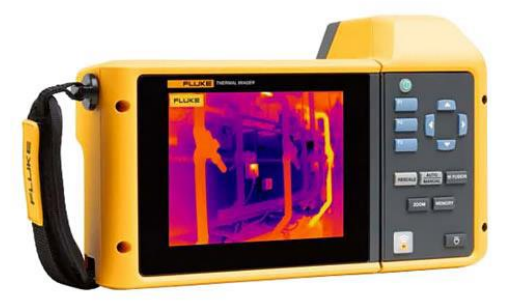

Figure 5 - Infrared Camera (Source: https://www.instrumart.com/products/43731/fluke-tix580-infrared-camera. Access in: 05/02/2021)

In material studies, thermography is usually applied in two different ways. Passive thermography investigates the specimen and its temperature variation without any thermal stimulus, being more adapted to in situ studies, such as bridges monitoring. Active thermography, on the other hand, is applied in controlled environments and revolves around heating the specimen to a determined temperature and capturing images during and after the heating process (Maldague et al., 2002).

In Mac et al. (2020), concrete specimens strengthened by carbon fiber-reinforced polymer sheets are put under active thermography for the detection of delamination defections. Four delamination were induced in the specimen. It was then heated by an artificial heat source provided by a set of halogen lamps. Because of the low thermal conductivity of concrete, the object was heated for a relatively long time, enough to reach the entire specimen, but not long enough to degenerate the thermal contrast resulted by the defects. Figure 6 shows the result of the thermography on the specimen.
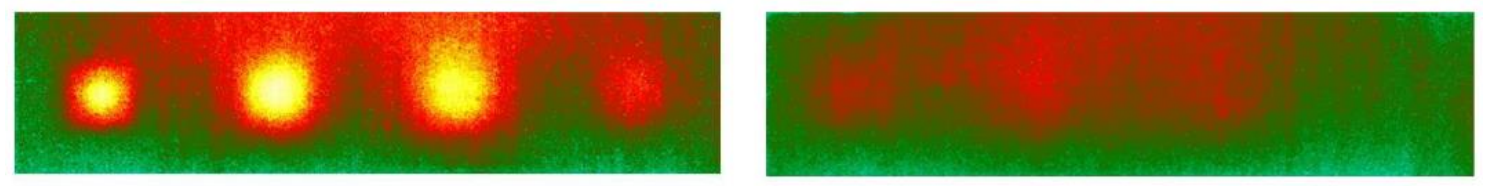

Figure 6 - Thermal image after 10 min of cooling under 15 min of heating from back-face (left) and thermal image after 40 min of cooling under 25 min of heating from front-face (right) (Mac et al. (2020)) 
On the other hand, Barreira et al. (2020) uses passive thermography in the evaluation of humidification in a lightweight concrete specimen by partially humidifying the bottom surface of the object and observing the thermal gradients in the concrete's surface as the moisture reaches more area. Figure 7 shows thermal images taken from the surface at different moments.

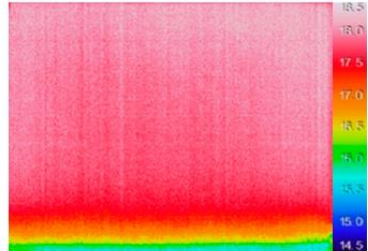

(a)

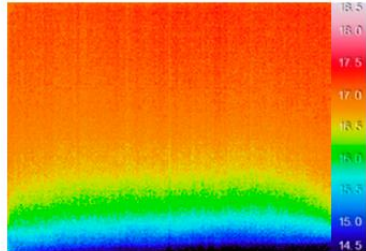

(b)

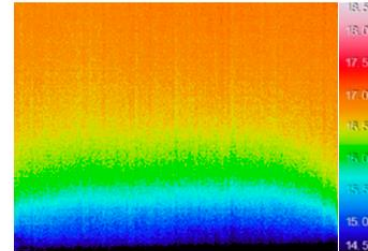

(c)

Figure 7 - Thermal images of the specimen's surface: (a) $t=0 \mathrm{~h} ;(\mathrm{b}) \mathrm{t}=4 \mathrm{~h} ;(\mathrm{c}) \mathrm{t}=24 \mathrm{~h}$ (Barreira et al. (2020))

\subsection{Ultrasonic Tomography}

Ultrasonic tomography consists in emitting sound waves through an object and measuring the velocity of propagation to investigate the specimen's interior. As a non-destructive test, it can be divided in two categories: Pulse Velocity Method (PVM) and Pulse Echo Method (PEM). PVM consists in the utilization of two sensors, being one emitter and another receptor. PEM on the other hand uses a single sensor that emits the sound waves and receives the echo. They both can be applied to several points in the specimen to produce similar results to those of micro-CT (Rahim et al., 2006).

In the context of concrete studies, some researchers proposed a table that indicates approximately the relationship between the velocity of propagation of the ultrasonic waves and the quality of the concrete (Hong et al., 2020; Karaiskos et al., 2015). Table 1 shows this relationship.

Table 1 - Concrete quality classification based on the velocity of ultrasonic waves (Hong et al., 2020;

Karaiskos et al., 2015)

\begin{tabular}{|c|c|}
\hline Ultrasonic wave velocity $(\mathrm{m} / \mathrm{s})$ & Concrete quality \\
\hline $\mathrm{V}>4500$ & Excellent \\
\hline $3500<\mathrm{V}<4500$ & Great \\
\hline $3000<\mathrm{V}<3500$ & Good \\
\hline $2000<\mathrm{V}<3000$ & Regular \\
\hline $\mathrm{V}<2000$ & Bad \\
\hline
\end{tabular}

In Słoński et al. (2020), ultrasonic tomography and convolutional neural networks are used to detect flaws in concrete specimens automatically. The results show an accuracy of $97 \%$ in detecting defects and classifying them. Figure 8 shows examples of scans done in the experiment.
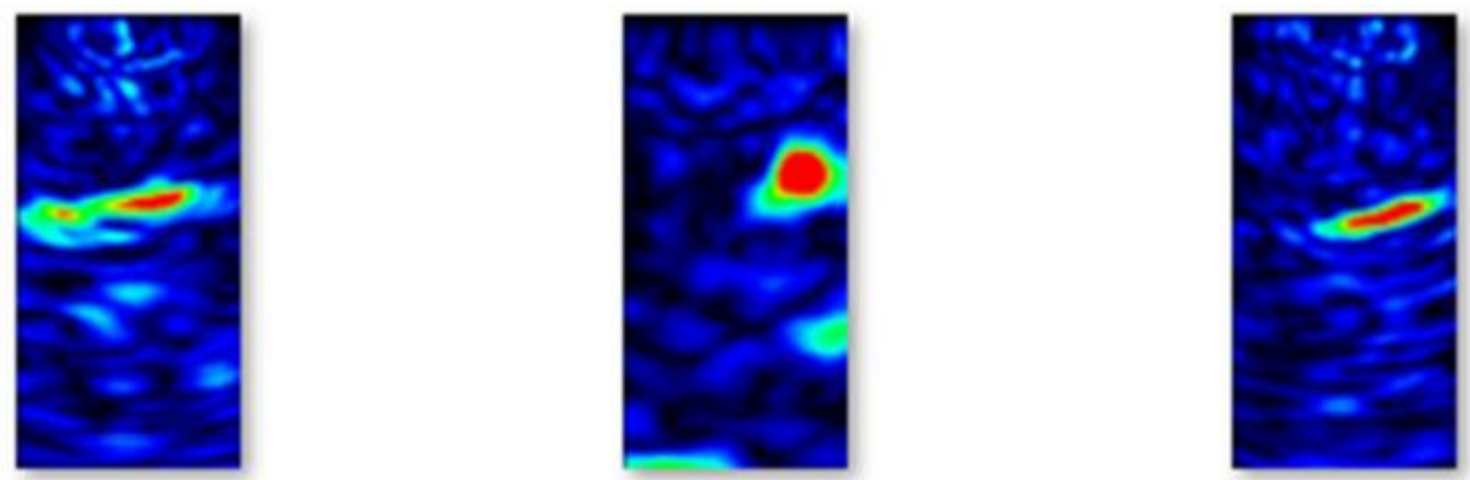

Figure 8 - Examples of scans of flawed specimens (Słoński et al. (2020)) 
The technique can also be used to predict the setting and compressive strength development times of concrete specimens at early ages using PVT, as seen in Lee and Lee (2020). To this end, various parameters such as water-to-cement ratio, curing conditions and aggregate types were examined to meet specific concrete strength values. The results show that the proposed model exhibited sufficient reliability when used to identify the nature change of concrete at early ages.

\subsection{Digital Image Correlation}

According to Bing (2018), DIC is an optical method based in images for global and local displacement measurements. It consists in comparing pairs of images taken from the surface of the specimen under different load stages. After the images are captured, a DIC software tracks specific sub-regions selected in one of the images on its pair, measuring the displacement of that place in the specimen.

The method has been applied to many different scopes, from metal or polymeric materials to composite materials and biological tissues, from macroscopic to nanoscale, from common laboratory conditions to outdoor conditions on extreme environments. In the aspect of concrete non-destructive studies, DIC is used as means to monitor damage in concrete beams.

On Lacidogna et al. (2020), DIC is used to damage monitor concrete beams coupled with other nondestructive methods. It analyses crack formation and propagation in concrete beam specimen and investigates fracture energy and bending strength. Figure 9 shows the measured strain on the specimen's surface.
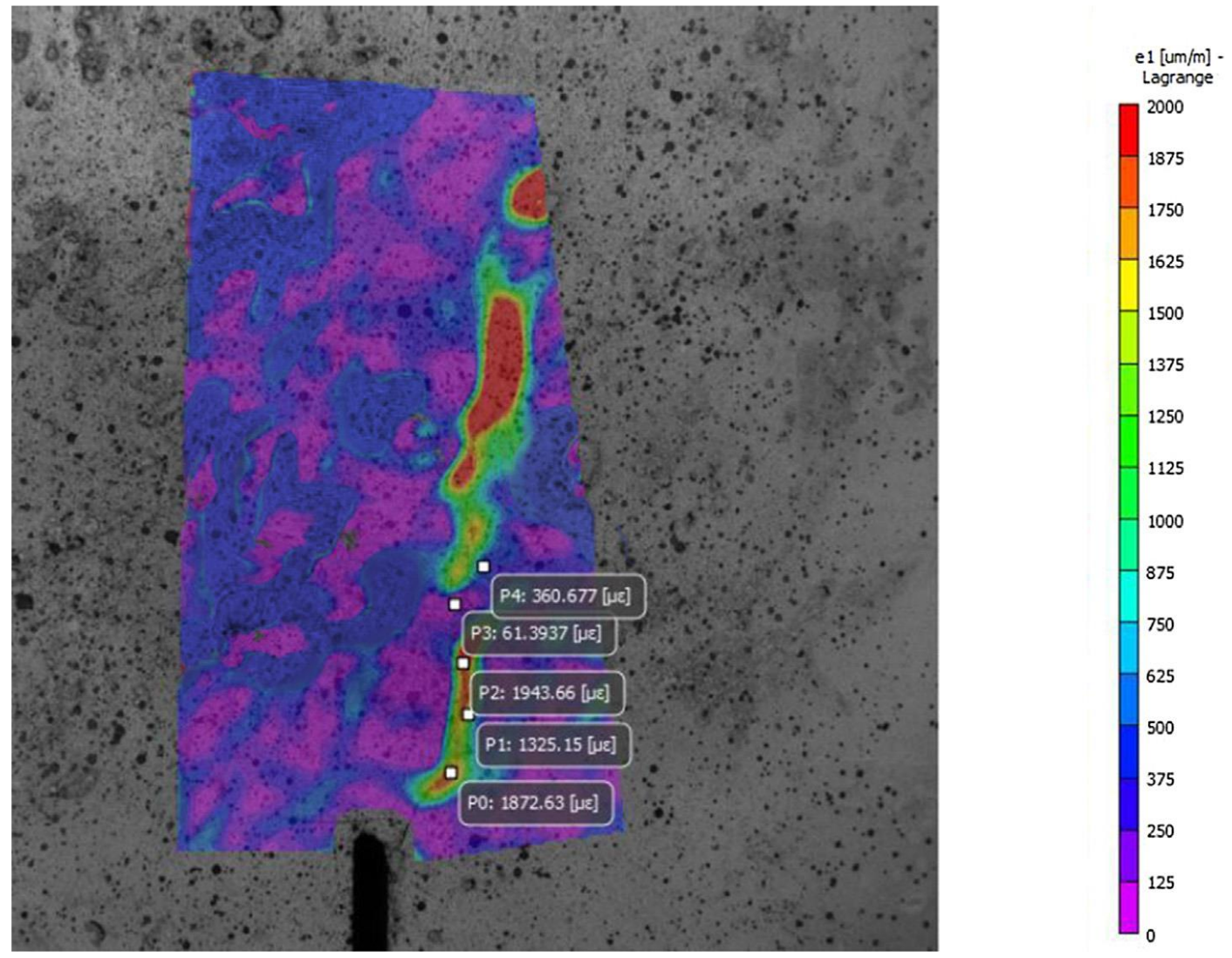

Figure 9 - Measured strain on the specimen's surface (Lacidogna et al. (2020))

In Ngeljaratan and Moustafa (2020), target tracking DIC is used to monitor the structural health and seismic response of concrete bridge structures. First, a bridge was tested in a large-scale laboratory application under bidirectional earthquake shaking and the dynamic response was measured by the method. Then, DIC was used to measure vibration frequencies of a footbridge in situ. Results show that DIC was successfully able to measure and monitor the bridges. Figure 10 shows a view of the footbridge monitored in situ. 


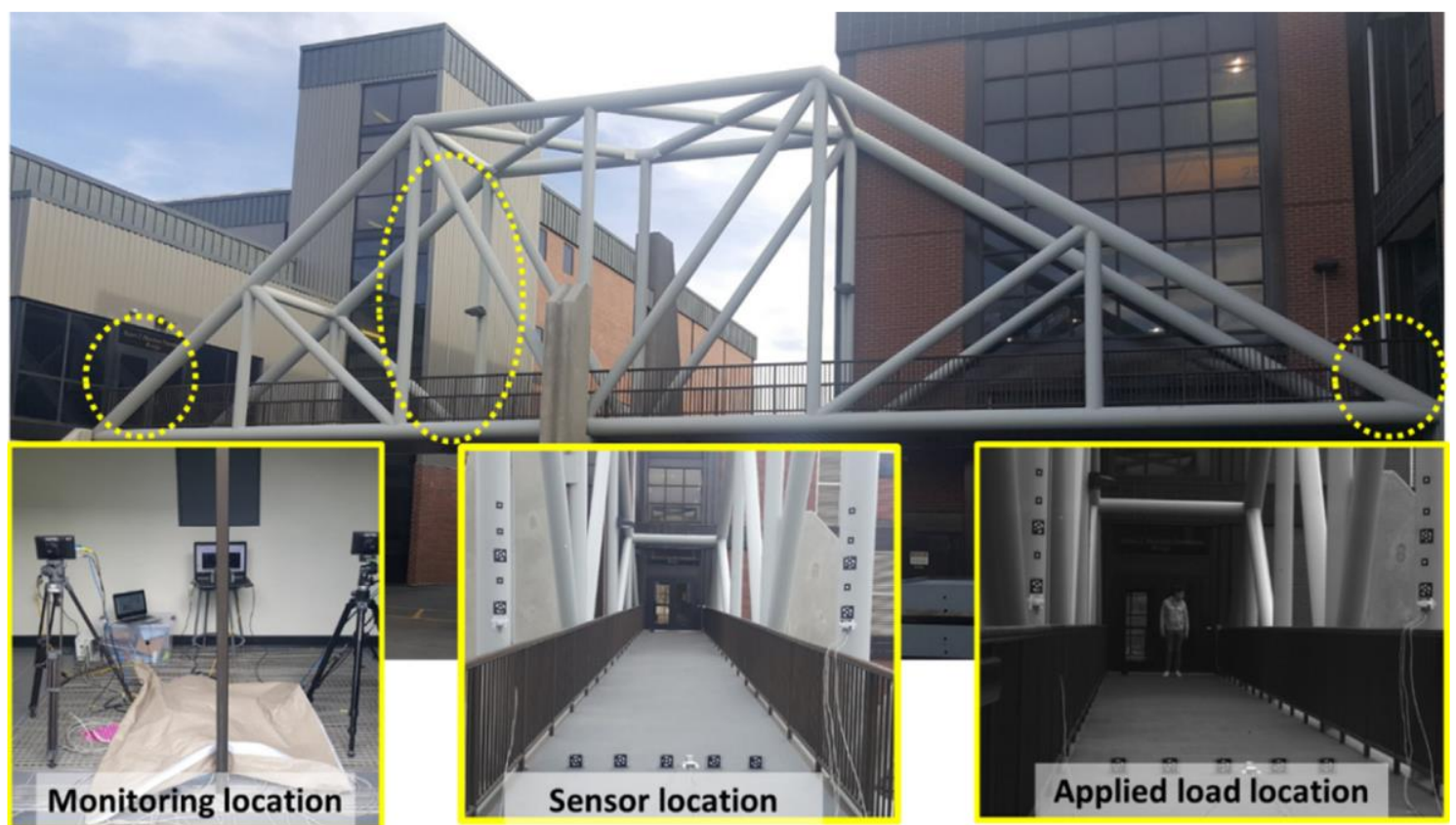

Figure 10 - Experimental setup for the monitored footbridge (Ngeljaratan and Moustafa (2020))

\section{Conclusions}

Based on the results obtained in this work, it is possible to affirm the growing interest in the study of nondestructive techniques for the analysis of concrete and structures. It is increasingly necessary to adapt or create methods that allow the diagnosis of these elements, to obtain a greater understanding of them. As in medicine, it is now possible to evaluate the interior of concrete structures, providing even more subsidies for researchers. Behind all the methods, the advancement of the equipment used, and the mathematics involved in the study process is notorious, which makes it possible to obtain several useful parameters regarding the concrete. Despite the great evolution, there is still much to discover, which makes the field of non-destructive testing completely open to new trends and discoveries.

\section{References}

Barreira, E., Almeida, R. M. S. F., Simões, M. L., \& Rebelo, D. (2020). Quantitative infrared thermography to evaluate the humidification of lightweight concrete. Sensors (Switzerland), 20(6), 1-14. https://doi.org/10.3390/s20061664

Beckmann, E. C. (2006). CT scanning the early days. British Journal of Radiology, 79(937), 5-8. https://doi.org/10.1259/bjr/29444122

Bing, P. (2018). DIC for surface deformation measurement: historical developments, recent advances and future goals.pdf. Measurement Science and Technology, 29, 1-32.

du Plessis, A., \& Boshoff, W. P. (2019). A review of X-ray computed tomography of concrete and asphalt construction materials. Construction and Building Materials, 199, 637-651. https://doi.org/10.1016/j.conbuildmat.2018.12.049

Hong, S., Yoon, S., Kim, J., Lee, C., Kim, S., \& Lee, Y. (2020). Evaluation of condition of concrete structures using ultrasonic pulse velocity method. Applied Sciences (Switzerland), 10(2). https://doi.org/10.3390/app10020706

Karaiskos, G., Deraemaeker, A., Aggelis, D. G., \& Van Hemelrijck, D. (2015). Monitoring of concrete structures using the ultrasonic pulse velocity method. Smart Materials and Structures, 24(11), 1-31. https://doi.org/10.1088/0964-1726/24/11/113001 
Lacidogna, G., Piana, G., Accornero, F., \& Carpinteri, A. (2020). Multi-technique damage monitoring of concrete beams: Acoustic Emission, Digital Image Correlation, Dynamic Identification. Construction and Building Materials, 242, 118114. https://doi.org/10.1016/j.conbuildmat.2020.118114

Lee, T., \& Lee, J. (2020). Setting time and compressive strength prediction model of concrete by nondestructive ultrasonic pulse velocity testing at early age. Construction and Building Materials, 252, 119027. https://doi.org/10.1016/j.conbuildmat.2020.119027

Mac, V. H., Huh, J., Doan, N. S., Shin, G., \& Lee, B. Y. (2020). Thermography-based deterioration detection in concrete bridge girders strengthened with carbon fiber-reinforced polymer. Sensors (Switzerland), 20(11), 1-19. https://doi.org/10.3390/s20113263

Maldague, X., Galmiche, F., \& Ziadi, A. (2002). Advances in pulsed phase thermography. Infrared Physics and Technology, 43(3-5), 175-181. https://doi.org/10.1016/S1350-4495(02)00138-X

Ngeljaratan, L., \& Moustafa, M. A. (2020). Structural health monitoring and seismic response assessment of bridge structures using target-tracking digital image correlation. Engineering Structures, 213(March), 110551. https://doi.org/10.1016/j.engstruct.2020.110551

Perlin, L. P. (2011). Tomografia Ultrassônica em Concreto: Desenvolvimento de Ferramenta Computacional. Universidade Federal de Santa Catarina.

Pham, L., Tran, P., \& Sanjayan, J. (2020). Steel fibres reinforced 3D printed concrete: Influence of fibre sizes on mechanical performance. Construction and Building Materials, 250, 118785. https://doi.org/10.1016/j.conbuildmat.2020.118785

Rahim, A., Taylor, S. L., Bush, N. L., ter Haar, G. R., Bamber, J. C., \& Porter, C. D. (2006). Physical parameters affecting ultrasound/microbubble-mediated gene delivery efficiency in vitro. Ultrasound in Medicine and Biology, 32(8), 1269-1279. https://doi.org/10.1016/j.ultrasmedbio.2006.04.014

Słoński, M., Schabowicz, K., \& Krawczyk, E. (2020). Detection of flaws in concrete using ultrasonic tomography and convolutional neural networks. Materials, 13(7), 1-16. https://doi.org/10.3390/ma13071557

Thomas, C., de Brito, J., Cimentada, A., \& Sainz-Aja, J. A. (2020). Macro- and micro- properties of multirecycled aggregate concrete. Journal of Cleaner Production, 245, 118843. https://doi.org/10.1016/j.jclepro.2019.118843 